\title{
THE SIMILARITY OF THE ACTION OF PHOSPHATIDYL- ETHANOLAMINE AND PLATELETS IN BLOOD COAGULATION
}

\author{
BY \\ J. R. O'BRIEN \\ From the Central Laboratory, Portsmouth and Isle of Wight Area Pathological Service, Milton Road, Portsmouth
}

(RECEIVED FOR PUBLICATION DECEMBER 12, 1955)

It has long been thought that some lipoid substance in platelets is responsible for their activity in the coagulation system in vitro, and this paper reports an attempt to identify its nature.

Erickson, Williams, Avrin, and Lee (1939) reported that platelets contained "cephalin" and Chargaff, Bancroft, and Stanley-Brown (1936) cephalin and lecithin fractions: Hougie (1955) suggested that material from platelets formed an integral part of intrinsic blood thromboplastin, and Chargaff, Bendich, and Cohen (1944) considered that a lipoprotein was the active substance in lung thromboplastin, which has many features in common with the intrinsic blood thromboplastin. Cobra venom has been known to be anticoagulant since 1881 (Morawitz), and also it is known to contain a strong lecithinase (Belfanti, Contardi, and Ercoli, 1936) called lecithinase A (see van Heyningen, 1951) as well as hyaluronidase (Chain and Duthie, 1940) and probably also a number of other unidentified enzymes (Martin and Lamb, 1907). These observations suggest that a lecithin-like phospholipoid might possibly be responsible for at least part of the activity of platelets.

Robinson and Poole (1956) have shown that the beneficial effect on the generation of thrombin during the coagulation of rat plasma poor in platelets by adding chylomicra is similar to that of adding phosphatidyl-ethanolamine (P.E.) and that hydrolysates of washed chylomicra indeed contain a phospholipoid indistinguishable from P.E.

It is not known whether platelets contain P.E., but the action of chylomicra and P.E. on the clotting of rat plasma as reported by Poole and Robinson (1956) and Robinson and Poole (1956) is so similar to the action of platelets that a comparison of P.E. and platelets seemed justified.

\section{Material}

Samples were obtained of ox brain lecithin, which was probably mainly oleyl-steryl-lecithin, of ox brain cepha- lin, which was probably a mixture of phosphatidylserine, phosphatidyl-ethanolamine, and inositol phosphatide, and of a preparation of ox brain phosphatidylèthanolamine (P.E.) and of a solution of ethanolamine. The P.E. was prepared by the classical method of Folch (1942) and represented his fraction five. It may have contained a little phosphatidyl-serine and lecithin, and, though dialysed, also a trace of amino-acids. Lovern (1952) claims that this fraction may contain an appreciable quantity of plasmalogen and a separation has not yet been reported. This preparation gave two spots on paper chromatography using the method of Lea, Rhodes, and Stoll (1955) with silica-impregnated paper. The samples of saturated and unsaturated egg P.E. were prepared by Dr. C. H. Lea (Lea $e t$ al., 1955), and had been shown to be over $99 \%$ pure.

For the enzymic experiments no attempt was made to isolate the active enzymes. The presence of several enzymes in cobra venom has been mentioned. Clostridium welchii $\alpha$ toxin contains a strong lecithinase $\mathrm{C}$ (Macfarlane and Knight, 1941) and some hyaluronidase (Zamecnik, Brewster, and Lipmann, 1947) ; it has been concentrated, but cannot be obtained in a pure state (van Heyningen and Bidwell, 1948). Bee venom has also been shown to contain lecithinase (Belfanti et al., 1936 ; Fleckenstein and Fettig, 1952). While these poisons were chosen because of their known lecithinase activity (see Fig. 1) the importance of their use in the

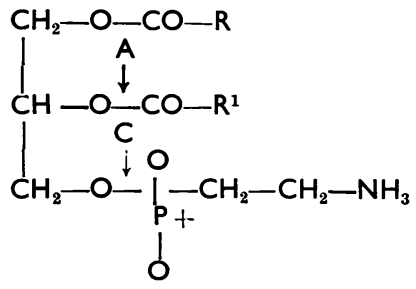

Fig. 1.-Formula of phosphatidyl ethanolamine; $\mathbf{R}$ and $\mathbf{R}^{\mathbf{1}}$ are fatty acids. The arrow $A$ indicates the site of action cf lecithinase $A$ (cobra venom) and the arrow $C$ indicates the site of action of lecithinase C (Clostridium welchii $\alpha$ toxin).

present work consisted in the comparison of their activities on suspensions of platelets with a suspension of P.E., and only one indirect attempt was made to check that they were active by virtue of their lecithinase content. 


\section{Preliminary Experiments}

Lecithin was found to be almost completely inactive in the coagulation of human plasma poor in platelets. Ethanolamine was found to be a strong inhibitor of the thrombin-fibrinogen reaction. Our sample of phosphatidyl-serine was found to have properties similar to P.E., but was in all respects considerably less active, and was probably inactive in the thromboplastin generation test. The mixed cephalin was as active as the Folchfractionated P.E.

\section{Activity of Platelets and Folch-fractionated P.E. Compared}

The Thrombin Generation Test.-A modification (O'Brien, 1955) of the thrombin generation test of Pitney and Dacie (1953) was used. To blood from a fasting volunteer was added a tenth part of $M$ this was centrifuged at 3,000 r.p.m. for 15 minutes and the supernatant plasma used as substrate. Platelets were washed four times and resuspended in saline and the final strength was usually about 500,000 per c.mm. Phosphatidyl-ethanolamine was suspended in distilled water at a concentration of $1 \mathrm{mg}$. per $\mathrm{ml}$. This substance was probably completely insoluble, but an emulsion was made by incubation at $37^{\circ} \mathrm{C}$. for 30 minutes. Differences in the result from day to day probably were partly caused from the degree of dispersion of the P.E.

From Table I it will be seen that the effect of the addition of P.E. to platelet-poor plasma is similar to that of the addition of platelets. Serial dilutions of platelets

TABLE I

COMPARISON OF PLATELETS AND P.E. USING "STYPVEN" TIME AND THROMBIN GENERATION TESTS

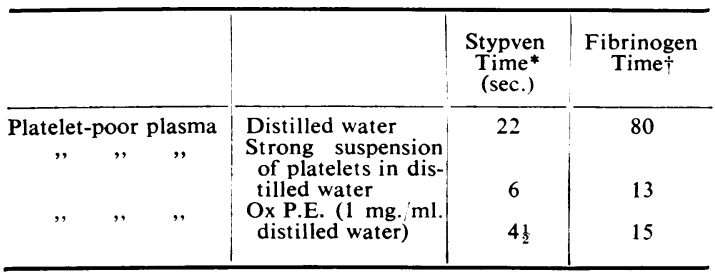

* Clotting time after adding $0.1 \mathrm{ml}$. of 10,000 solution of Russell viper venom to $0.1 \mathrm{ml}$. of the two reacting substances and finally 0.1 ml. of $\mathrm{M} / 40 \mathrm{CaCl}_{2}$.

+ Shortest fibrinogen time in sub-tube after recalcification in the † Shortest fibrinogen time in sub-tube after recalcification in the
thrombin generation test, using $0.3 \mathrm{ml}$. of platelet-poor plasma and $0.2 \mathrm{ml}$. of the additional substances and $0.3 \mathrm{ml} . \mathrm{M} 40 \mathrm{CaCl}_{2}$.

and P.E. tested in a similar way produced similar curves when the fibrinogen times were plotted against the dilutions.

Russell Viper Venom Accelerated Clotting (Stypven) Time.-The addition of $0.1 \mathrm{ml}$. of a 1 in 10,000 dilution of Russell viper venom ("stypven," Burroughs Wellcome and Co.) to $0.1 \mathrm{ml}$. of platelet-poor plasma gave a clotting time on recalcification of 22 seconds (Table I). The addition of platelets reduced this time to 6 seconds, and the addition of P.E. gave a time of $4 \frac{1}{2}$ seconds.

Effective Concentration of P.E. and Platelet Phospholipoid Compared.-Erickson et al. (1939) have reported that $68 \%$ of the dried weight of ox platelets is phospholipoid and that $12 \%$ of this was said to be "kephalin."
The dry weight of one of our preparations of platelets was $18.7 \mathrm{mg}$. per $\mathrm{ml}$., and therefore, if human platelets are approximately of the same composition as those of the ox, our preparation contained $1.6 \mathrm{mg}$. "kephalin" per $\mathrm{ml}$. This platelet preparation was found to be approximately as active as a fivefold dilution of the standard $1 \mathrm{mg}$. per ml. dilution of P.E., i.e., as active as a Folch fraction of P.E. in a concentration of $0.2 \mathrm{mg}$. per ml.

There are, however, a number of uncertainties, and these rough calculations can prove nothing. It is not known how much P.E. was in an active form, or how much cephalin there is in human platelets, or how much of the cephalin is P.E. or other active substance. The fact that these concentrations are of the same order is at least compatible with the assumption that the "kephalin" fraction of platelets contains the active agent.

Thromboplastin Generation Test.-For this test it 9 seemed even more important to obtain the P.E. in a finely dispersed state. However, normal clotting times of 10 seconds or less in the sub-sample tubes have repeatedly been obtained by substituting P.E. for platelets.

Heat Stability.-The activity of platelets in the thrombin generation test and in the thromboplastin generation test is not appreciably diminished by autoclaving a neutral saline suspension at $20 \mathrm{lb}$. pressure for 30 minutes. Phosphatidyl-ethanolamine is similarly unaffected.

Effect of Acid and Alkaline Hydrolysis.-Suspensions of platelets and P.E. were brought to $p \mathrm{H} 2$ by the addition of $\mathrm{N} 10$ hydrochloric acid and to $p \mathrm{H} 10$ by the addition of $\mathrm{N} / 10$ sodium hydroxide, and the four mixtures were boiled for 10 minutes. After adjusting the $p \mathrm{H}$ to neutrality, all four mixtures were found to give the same times as the controls in the Russell viper venom accelerated clotting times.

Absorption by Alumina.-Alumina has a special ability to absorb phospholipoids. If platelets are washed in saline five times and the platelet deposit is then left in contact with saline for 30 minutes and afterwards centrifuged at 3,000 r.p.m. it will be found that the supernatant saline, largely freed of platelet bodies, will have active, platelet-like activity, as judged by the thrombin generation and thromboplastin generation tests. If this supernatant is absorbed for 30 minutes with alumina, using five times as much as would be used in the preparation of plasma in the thromboplastin generation test, the supernatant is found to have become completely inactive. The suspension of P.E. is similarly inactivated.

Inactivation by Cobra Venom and Clostridium welchii $\alpha$ Toxin.-To a suspension of P.E. was added an equal part of cobra venom (Naja nigrocollis), $1 \mathrm{mg}$. per $\mathrm{ml}$. To another tube containing P.E. equal parts of $\alpha$ toxin $\left(50 \mathrm{mg} . / \mathrm{ml}\right.$.) and of $\mathrm{M} / 40 \mathrm{CaCl}_{2}$ were added, and the appropriate controls set up (Table II). These seven tubes were incubated at $37^{\circ} \mathrm{C}$. for 30 minutes and the enzymes destroyed by autoclaving at a pressure of $20 \mathrm{lb}$. for 30 minutes. The mixtures were then tested in the 
TABLE II

COMPARISON OF PLATELETS WITH OX P.E. TREATED WITH COBRA VENOM AND $\alpha$ TOXIN*

\begin{tabular}{|c|c|c|c|c|c|c|c|c|}
\hline & & & & $\begin{array}{l}\text { Shortest } \\
\text { Fibrinogen } \\
\text { Time } \\
\text { (sec.) }\end{array}$ & & & & $\begin{array}{l}\text { Shortest } \\
\text { Fibrinogen } \\
\text { Time } \\
\text { (sec.) }\end{array}$ \\
\hline Platelet-poor plasma + saline + saline & $\cdots$ & $\cdots$ & $\cdots$ & 73 & Platelet-poor plasma + saline + saline & $\cdots$ & $\cdots$ & 60 \\
\hline $\begin{array}{l}\text { Platelet-poor plasma + saline + PE } / 5 \\
\text { Platelet-poor plasma + cobra + PE } / 5 \\
\text { Platelet-poor plasma + cobra + saline }\end{array}$ & $\begin{array}{l}\cdots \\
\cdots \\
\cdots\end{array}$ & $\begin{array}{l}\cdots \\
\cdots \\
\cdots\end{array}$ & $\begin{array}{l}\cdots \\
\cdots \\
\cdots\end{array}$ & $\begin{array}{l}22 \\
73 \\
74\end{array}$ & $\begin{array}{l}\text { Platelet-poor plasma + saline + platelets } \\
\text { Platelet-poor plasma + cobra + platelets } \\
\text { Platelet-poor plasma + cobra + saline }\end{array}$ & $\begin{array}{l}\cdots \\
\cdots \\
\cdots\end{array}$ & $\begin{array}{l}\cdots \\
\cdots \\
\cdots\end{array}$ & $\begin{array}{l}30 \\
54 \\
76\end{array}$ \\
\hline \multicolumn{3}{|c|}{$\begin{array}{l}\text { Platelet-poor plasma }+ \text { saline and } \mathrm{CaCl}_{2} \text { and } \mathrm{PE} / 3 \\
\text { Platelet-poor plasma }+\alpha \text { toxin and } \mathrm{CaCl}_{2}+\mathrm{PE} / 3 \\
\text { Platelet-poor plasma }+\alpha \text { toxin and } \mathrm{CaCl}_{2}+\text { saline }\end{array}$} & $\begin{array}{l}\cdots \\
\cdots\end{array}$ & $\begin{array}{l}23 \\
50 \\
52\end{array}$ & \multicolumn{3}{|c|}{$\begin{array}{l}\text { Platelet-poor plasma }+ \text { saline and } \mathrm{CaCl}_{2}+\text { platelets } \\
\text { Platelet-poor plasma }+\alpha \text { toxin and } \mathrm{CaCl}_{2}+\text { platelets } \\
\text { Platelet-poor plasma }+\alpha \text { toxin and } \mathrm{CaCl}_{2}+\text { saline }\end{array}$} & $\begin{array}{l}22 \\
44 \\
50\end{array}$ \\
\hline
\end{tabular}

* To $0.5 \mathrm{ml}$. of the appropriate dilution of P.E. $1 \mathrm{mg} . / \mathrm{ml}$. saline, or to $0.5 \mathrm{ml}$. of platelets, was added $0.5 \mathrm{ml}$. of venom $1 \mathrm{mg}$. $/ \mathrm{ml}$. saline, or $0.5 \mathrm{ml}$. of $a$ toxin $47 \mathrm{mg}$. ml. saline, or $0.5 \mathrm{ml}$. of saline; after 30 minutes' incubation at $37^{\circ} \mathrm{C}$. the tubes were autoclaved and $0.2 \mathrm{ml}$. of the contents added to the thrombin generation test using $0.3 \mathrm{ml}$. of platelet-poor plasma as the substrate.

thrombin generation test and both enzymes were found to have inactivated the P.E. Platelets were similarly inactivated and sometimes more completely by using more dilute $\alpha$ toxin.

These results, which were repeatedly confirmed, seem to be at variance with those of Macfarlane (1942) and Zamecnik et al. (1947), who worked with a much more dilute solution and state that $\alpha$ toxin is a specific lecithinase, with a slow reaction only on phosphatidyl-serine, although Zamecnik found slight activity of $\alpha$ toxin on P.E. but was not sure if it was due to impurities in the P.E. It is possible that different batches of $\alpha$ toxin contain a different series of enzymes ; a very strong solution of $\alpha$ toxin was used. Furthermore, Long and Maguire (1954) have shown that the activity of $\alpha$ toxin, at any rate on lecithin, is influenced by the nature of the fatty acids in the molecule.

Inactivation by Bee Venom.-Bee venom is said to contain a lecithinase (Belfanti et al., 1936). It is difficult to destroy : it resists boiling at $p \mathrm{H} 2,7$, and 10 , and sometimes survives when autoclaved for 30 minutes at a pressure of $20 \mathrm{lb}$. However, a solution made from the dried venom extruded from about 50 bees was dissolved into $3 \mathrm{ml}$. saline. Equal parts of this solution and a platelet suspension were mixed in one tube and a suspension of P.E. and venom solution in another, and appropriate controls

TABLE III

COMPARISON OF PLATELETS AND OX P.E. TREATED BY BEE VENOM

\begin{tabular}{ll|c|c}
\hline & $\begin{array}{c}\text { Russell Viper } \\
\text { Venom Time } \\
\text { (sec.) }\end{array}$ & $\begin{array}{c}\text { Fibrinogen Time } \\
\text { (sec.) }\end{array}$ \\
\hline Saline+saline & $\ldots$ & 24 & 60 \\
Saline+bee. & $\ldots$ & 25 & 66 \\
Platelets+saline & $\ldots$ & 11 & 26 \\
Platelets +bee & $\ldots$ & 25 & 60 \\
P.E.+ saline & $\ldots$ & 10 & 17 \\
P.E.+bee .. & $\ldots$ & 28 & 54 \\
\hline
\end{tabular}

A platelet suspension and a suspension of P.E., $0.2 \mathrm{mg}$. $\mathrm{ml}$., and controls were incubated at $37^{\circ} \mathrm{C}$. for 30 minutes with bee venom. The venom was then inactivated by autoclaving at $20 \mathrm{lb}$. pressure for 30 venom was then inactivated by autoclaving at 20 lb. pressure for 30
minutes and the suspensions were added to platelet-poor plasma and
tested by estimating the Russell viper venom accelerated time and the fibrinogen by the thrombin generation test. were set up (Table III). All the tubes were incubated at $37^{\circ} \mathrm{C}$. for 30 minutes. The venom was then destroyed by autoclaving for 30 minutes at $20 \mathrm{lb}$. pressure, and the activity of the P.E. and platelets was investigated by adding them to platelet-poor fasting human plasma and estimating the Russell viper venom accelerated clotting time and the fibrinogen times in the thrombin generation test.

Formation of Haemolytic Substance in Digestion by Cobra and Bee Venoms.-Both platelets and P.E. were incubated with cobra venom and with bee venom for 30 minutes. The venoms were then destroyed by autoclaving, and both platelet suspension and P.E., after incubating with cobra venom, were found to have become haemolytic when introduced into a suspension of washed red cells. Bee venom, like cobra venom, is itself haemolytic, but P.E. and platelets were not rendered haemolytic by incubation with bee venom and subsequent inactivation of the bee venom.

Clot Retraction.-When plasma poor in platelets clots there is no clot retraction. The addition of sufficient fresh platelets produces marked clot retraction. Autoclaving or freezing platelets destroys this activity, in no way affecting the activity of platelets in the various clotting tests. Phosphatidyl-ethanolamine, like boiled platelets, did not produce clot retraction.

Inactivation by Diazomethane.-Diazomethane reacts entirely specifically on the amino-phospholipoids as

TABLE IV

COMPARISON OF PLATELETS AND OX P.E. TREATED WITH DIAZOMETHANE

\begin{tabular}{|c|c|c|}
\hline & $\begin{array}{c}\text { Stypven } \\
\text { Time* } \\
\text { (sec.) }\end{array}$ & $\begin{array}{c}\text { Fibrinogen } \\
\text { Time } \\
\text { (sec.) }\end{array}$ \\
\hline 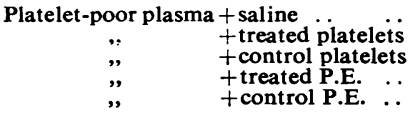 & $\begin{array}{r}26 \\
22 \\
8 \\
15 \\
5 \frac{1}{2}\end{array}$ & $\begin{array}{l}87 \\
75 \\
19 \\
82 \\
14\end{array}$ \\
\hline
\end{tabular}

- Russell viper venom accelerated clotting time.

$\dagger$ Fibrinogen time in thrombin generation test.

For "treatment" of platelets and ox phosphatidyl ethanolamine (P.E.) see text. 
opposed to the lecithins, and Baer and Maurukas (1955) have shown that when kephalins are treated with this substance the base is completely removed with the substitution of two methyl groups.

Samples of dried platelets and ox P.E. in $0.5 \mathrm{ml}$. chloroform and $2 \mathrm{ml}$. ether were exposed overnight at room temperature to diazomethane. The diazomethane was present in about 200 -fold molar excess. The solvent and excess reagent were removed by a stream of nitrogen and the samples were then exposed to a high vacuum for three hours. Other samples were treated identically with the solvent but without diazomethane. The activity of both platelets and P.E. in the clotting tests was destroyed by this treatment (Table IV).

Activity of Alumina, $\propto$ Toxin, and Bee and Cobra Venoms on Thromboplastin Test.-The four substances which have been shown to inactivate plateletsaluminia, $\propto$ toxin, cobra venom, and bee venom-were adjusted to such a strength that, introduced into the reacting mixture of the normal thromboplastin generation test, they all grossly impaired the production of thromboplastin. It was found that if they were introduced at these strengths into the sub-tubes containing the platelet-poor plasma they did not affect the clotting times of the plasma when active thromboplastin was transferred from a normal control reacting tube. Furthermore, a normal thromboplastin generation test was set up with normal alumina plasma, serum, and platelets, and recalcified, and the generation of thromboplastin was observed by the usual sub-sampling. After about three minutes, when maximal thromboplastin activity was present in the reacting tube as evidenced by the clotting of the sub-sample tube in about 10 seconds, then either alumina or cobra venom or bee venom or $\alpha$ toxin in the same strength as before was introduced into the reacting tube and further sub-samples taken. The times of the subsequent sub-sample tubes were not affected by these additions.

\section{Comparison of the Activity of Pure Egg P.E. and Platelets}

The very pure samples of egg P.E., saturated and unsaturated, were available only in small quantities, were unstable, and did not allow extended tests. It was found impossible to produce a smooth aqueous emulsion, although boiling, shaking with glass beads, the addition

TABLE V

A COMPARISON OF iPLATELETS -AND EGG P.E.

\begin{tabular}{|c|c|c|c|}
\hline & $\begin{array}{l}\text { Fibrinogen } \\
\text { Time } \\
\text { (sec.) }\end{array}$ & $\begin{array}{l}\text { Sub-tube } \\
\text { Time } \\
\text { (sec.) }\end{array}$ & $\begin{array}{c}\text { Stypven } \\
\text { Time } \\
\text { (sec.) }\end{array}$ \\
\hline $\begin{array}{ll}\text { Saline } & \ldots \\
\text { Platelets } & \ldots \\
\text { Saturated P.E. } & \ldots \\
\text { Unsaturated P.E. } \\
\text { Saline }\end{array}$ & $\begin{array}{l}66 \\
15 \\
38 \\
31 \\
67\end{array}$ & $\begin{array}{l}42 \\
11 \\
27 \\
25 \\
50\end{array}$ & $\begin{array}{r}20 \frac{1}{2} \\
5 \\
13 \frac{1}{2} \\
11 \frac{1}{2} \\
20 \frac{1}{2}\end{array}$ \\
\hline
\end{tabular}

Thrombin generation tests, thromboplastin generation tests, and stypven accelerated clotting times were carried out. The tests were carried out normally but in the absence of platelets, then with the addition of a strong suspension of platelets or P.E., $5 \mathrm{mg} . \mathrm{ml}$. of lecithin, and the addition of a few drops of ether which was subsequently evaporated were methods tried. However, suspensions of these substances were repeatedly compared with platelets in the thrombin generation test, in the thromboplastin generation test, and in the " stypven" accelerated clotting time test (Table V).

\section{Conclusions}

There is a striking similarity in the behaviour of platelets and ox P.E. in these various tests, and in particular the similarity of the response of both to diazomethane and four different enzyme-containing substances, three of which, cobra, Russell viper venom, and $\alpha$ toxin, at least are known to contain completely different kinds of enzymes. The observation that platelets and P.E. become haemolytic when treated with cobra venom can only mean that this venom contains phospholipase $\mathrm{A}$ and is converting the phospholipoids in both the sample of P.E. and in platelets into a lyso compound. The only point of dissimilarity is that P.E., like boiled platelets, does not cause clot retraction whereas normal platelets do; yet boiled platelets retain their activity in the various clotting tests. If clot retraction is due to the action of the intact platelets and is not a vital part of the coagulation process, this dissimilarity is accounted for. Since bee venom inactivated P.E. and platelets as judged by the clotting tests and did not produce a haemolytic product, it is possible that this venom contains a lecithinase $\mathrm{A}$ and $\mathrm{B}$.

It will have been noted that in no case was the pure egg P.E. nearly as active as platelets, and so, by inference, as the ox P.E., yet the egg P.E. showed some activity in all tests. It cannot be established whether the difference in activity between these pure substances and the less pure Folch fraction from ox brain is due to the presence of an active impurity in the Folch fraction or to the greater difficulty in artively dispersing the purer substances. It must be remembered that our possibly impure phosphatidyl-serine showed some activity, and the inositol compounds were not investigated, although Poole and Robinson (1956) found both inactive in the Russell viper venom accelerated clotting time. also both inactive in promoting thrombin generation (Robinson and Poole, 1956). So it is not established that ethanolamine is the only possible radicle that could be active. We also have no evidence about the nature of fatty acid radicles involved. However, the evidence strongly suggests that the activity of platelets in the clotting systems in vitro is due to a phosphatidyl-ethanolamine or to some closely related substance.

Robinson and Poole (1956) reported that rat chylomicra probably contained some P.E., and 
O'Brien (1955) has shown that the observed acceleration of clotting after a fatty meal in man is unlikely to be due solely to intact chylomicra. If the chylomicra are constantly being "cleared", (Hahn, 1943) in the blood stream, then it is possible that the P.E. becomes more available and active in the plasma, although this is not proved, and there are other possible explanations of O'Brien's observations. These findings might also explain why this post-prandial phenomenon is masked by the presence of platelets, since it is suggested that platelets contain an excess of the same or similar phospholipoid.

The results of introducing cobra venom, bee venom, $\alpha$ toxin, and alumina into the thromboplastin test strongly suggest that the platelet phospholipoid alone or combined as an intermediate product is in such a state that it can be inactivated by these poisonous substances only up to the moment that thromboplastin is formed, and that complete thromboplastin is not capable of such inactivation. (The possibility of an enzymatic effect on other components of the system is not excluded.)* Hougie (1955) has suggested that particulate material from platelets is actually incorporated in the active thromboplastin. If this is so, from the above evidence it seems certain that in thromboplastin the platelet moiety is in a form different from that in the original platelets.

\section{Summary}

Platelets play an essential part in the normal thrombin generation test and in the thromboplastin test. If phosphatidyl-ethanolamine is substituted for platelets in these tests the results are essentially the same. The effect on the "stypven" clotting time of the addition of platelets to platelet-poor plasma is the same as the addition of P.E. Both platelets and P.E. are inactivated by cobra venom, by bee venom, by Clostridium welchii $\alpha$ toxin, and by diazomethane, and are absorbed by alumina. This strongly suggests that the substance in platelets which is active in these tests is a phosphatidylethanolamine or some closely related compound. There is an increase in circulating chylomicra after a fatty meal, and Robinson and Poole (1956) have shown that the chylomicra probably contain P.E.

* It has now been shown that cobra venom also damages plasma. This venom appears to inactivate the Christmas factor (P.T.C.) since platelet-rich cobra-treated plasma can be corrected by the addition of normal serum, but is not corrected by the addition of serum from of normal serum, but is not corrected by the
cases of Christmas disease (O'Brien, 1956).
The chylomicra rapidly disappear in the post-prandial period and may be broken down in the blood stream. If this is so the free P.E. (or P.E.-like substance) may be at least partly responsible for the post-prandial acceleration of blood clotting.

It has also been shown in the thromboplastin generation test that $\alpha$ toxin, cobra venom, bee venom, and alumina, presumably acting on the platelet phospholipoid alone or in some combination, ${ }^{*}$ are all capable of preventing the formation of thromboplastin. Intrinsic thromboplastin once formed is not inactivated. If the phospholipoid molecule is incorporated in the active thromboplastin of the thromboplastin generation test it must be in some form different from that in the original platelets.

My thanks are due first to the Medical Research Council for a grant for technical assistance. I am most grateful to Dr. D. N. Rhodes for treating samples of dried plate'ets and ox P.E. with diazomethane, and to Mrs. J. B. Cheater, A.I.M.L.T., for carrying out the very large number of experiments involved in this work. I gratefully acknowledge the great help I have received from Dr. R. G. Macfarlane and Dr. J. C. F. Poole for advice and help at all stages of this work. I must also thank Dr. J. N. Hawthorne and Mr. R. Dils for the Folch fractions of ox phospholipoids and Dr. C. $\mathrm{H}$. Lea for the pure egg phosphatidyl-ethanolamines.

REFERENCES

Baer, E., and Maurukas, J. (1955). J. biol. Chem., 212, 39.

Belfanti, S., Contardi, A., and Ercoli, A. (1936). Ergebn. Enzymforsch., 5, 213.

Chain, E., and Duthie, E. S. (1940). Brit. J. exp. Path., $21,324$.

Chargaff, E., Bancroft, F. W., and Stanley-Brown, M. (1936). J. biol. Chem., 116, 237.

- Bendich, A., and Cohen, S. S. (1944). Ibid., 156, 161.

Erickson, B. N., Williams, H. H., Avrin, I., and Lee, P. (1939). J. clin. Invest., 18, 81 .

Fleckenstein, A., and Fettig, O. (1952), Arch. exp. Path. Pharmak., 216, 415 .

Folch, J. (1942). J. biol. Chem., 146, 31.

Hahn, P. F. (1943). Science, 98, 19.

Hougie, C. (1955). Brit. J. Haemat., 1, 213.

Lea, C. H., Rhodes, D. N., and Stoll, R. D. (1955). Bicchem. J., 60, 353.

Long, C., and Maguire, M. F. (1954). Ibid., 57, 223.

Lovern, J. A. (1952). Ibid., 51, 464.

Macfarlane, M. G. (1942). Ibid., 36, Nos. 1 and 2, III.

and Knight, B. C. J. G. (1941). Ibid., 35, 884.

Martin, C. J., and Lamb, G. (1907). In Allbut t and Rolleston's $A$ System of Medicine, vol. 2, pt. 2, p.783. Macmillan, London.

Morawitz, P. (1881). Ergebn. Physiol., 277.

O'Brien, J. R. (1955). Lancet, 2, 690.

- (1956). Ibid. (in the press).

Pitney, W. R., and Dacie, J. V. (1953). Journal of Clinical Pathology, 6,9 .

Poole, J. C. F., and Robinson, D. S. (1956). Quart. J. exp. Physiol.,

41, 31.
Robinson, D. S., and Poole, J. C. F. (1956). Ibid., 41, 36.

Van Heyningen, W. E. (1951). Annual Reports on the Progress of Chemistry, 1950, 47, 303.

and Bidwell. E. (1948). Biochem. J., 42, 130.

Zamecnik, P. C., Brewster, L. E., and Lipmann, F. (1947). J. exp. Med., 85, 381 . 